\title{
Hydrogen-bond network probed by time-resolved optoacoustic spectroscopy: photoactive yellow protein and the effect of E46Q and E46A mutations
}

\author{
Aba Losi, $\dagger^{a}$ Thomas Gensch, $\ddagger^{a b}$ Michael A. van der Horst, ${ }^{b}$ Klaas J. Hellingwerf ${ }^{b}$ and \\ Silvia E. Braslavsky*a \\ ${ }^{a}$ Max-Planck-Institut für Bioanorganische Chemie (formerly Strahlenchemie), Postfach \\ 101365,D-45413 Mülheim an der Ruhr,Germany.E-mail: braslavskys@mpi-muelheim.mpg.de \\ ${ }^{\boldsymbol{b}}$ Laboratory for Microbiology, Swammerdam Institute for Life Sciences, BioCentrum, \\ University of Amsterdam, Nieuwe Achtergracht 166, 1018 WV Amsterdam, The Netherlands
}

Received 20th December 2004, Accepted 7th April 2005

First published as an Advance Article on the web 25th April 2005

The enthalpy and structural volume changes $\left(\Delta H_{i}\right.$ and $\left.\Delta V_{i}\right)$ produced upon photoinduced formation and decay of the red-shifted intermediate $\left(\mathrm{pR}=\mathrm{I}_{1}\right)$ in the photoactive yellow protein (WT-PYP) from Halorhodospira halophila and the mutated E46Q-PYP and E46A-PYP, were determined by laser-induced optoacoustic spectroscopy (LIOAS) using the two-temperatures method, at $\mathrm{pH}$ 8.5. These mutations alter the hydrogen bond between the phenolate oxygen of the chromophore and the residue at position 46. Hydrogen bonding is still possible in E46QPYP via the $\delta-\mathrm{NH}_{2}$ group of glutamine, whereas it is no longer possible with the methyl group of alanine in E46A-PYP. In all three proteins, $\mathrm{pR}$ decays within hundreds of ns to $\mu$ s into the next intermediate, $\mathrm{pR}^{\prime}$. The $\Delta H$ values for the formation of $\mathrm{pR}\left(\Delta H_{\mathrm{pR}}\right)$ and for its decay into $\mathrm{pR}^{\prime}\left(\Delta H_{\left.\mathrm{pR} \rightarrow \mathrm{pR}^{\prime}\right)}\right)$ are negligibly affected by the E46Q and the E46A substitution. In all three proteins the large $\Delta H_{\mathrm{pR}}$ value drives the photocycle. Whereas $\Delta V_{\mathrm{pR}}$ is a similar contraction of $c a .15 \mathrm{ml} \mathrm{mol}{ }^{-1}$ for E46Q-PYP and WT-PYP, attributed to strengthening the hydrogen bond network (between 4 and 5 hydrogen bonds) inside the protein chromophore cavity, an expansion is observed for E46A-PYP, indicating just an enlargement of the chromophore cavity upon chromophore isomerization. The results are discussed in the light of the recent time-resolved room temperature, crystallographic studies with WT-PYP and E46Q-PYP. Formation of $\mathrm{pR}^{\prime}$ is somewhat slower for E46Q-PYP and much slower for E46A-PYP. The structural volume change for this transition, $\Delta V_{\mathrm{pR} \rightarrow \mathrm{pR}^{\prime}}$, is relatively small and positive for WT-PYP, slightly larger for E46Q-PYP, and definitely larger for the hydrogen-bond lacking E46A-PYP. This indicates a larger entropic change for this transition in E46A-PYP, reflected in the large pre-exponential factor for the $\mathrm{pR}$ to $\mathrm{pR}^{\prime}$ decay rate constant determined in the $5-30{ }^{\circ} \mathrm{C}$ temperature range. This decay also shows an activation entropy that compensates the larger activation energy in E46A-PYP, as compared to the values for WT-PYP and E46Q-PYP.

\section{Introduction}

Photoactive yellow protein (PYP) is a blue-light photoreceptor, thought to be responsible for the negative phototactic response in Halorhodospira halophila. ${ }^{1}$ PYP contains a single PAS [PerArntSim] domain, ${ }^{2}$ binding 4-hydroxycinnamic acid as its chromophore, via a thiol-esther bond with cysteine $69 .{ }^{3,4}$ In the PYP ground state, $\mathrm{pG}\left(\lambda_{\max }=446 \mathrm{~nm}\right)$, the chromophore has its vinyl group in the trans configuration ${ }^{5}$ and is deprotonated as a phenolate. ${ }^{4,6}$ The phenolate oxygen participates in a hydrogen bond (HB) network with glutamate 46 , tyrosine 42 , and threonine $50 .^{5,7}$ The HB network lowers the $\mathrm{p} K_{\mathrm{a}}$ of the phenolic group from 8.8 in the free chromophore to about 3 in the protein. ${ }^{8-10}$ The mechanism of the PYP photocycle can be described in simple terms as follows: Upon blue-light excitation the chromophore undergoes isomerization into the cis form. This drives $\mathrm{pG}$ into the red-shifted $\mathrm{pR}$ (also called $\mathrm{I}_{1}$ ) intermediate $\left(\lambda_{\max }=465 \mathrm{~nm}\right)$ within $3 \mathrm{~ns}$ at room temperature. $\mathrm{pR}$ decays into the long-lived, blue shifted species, $\mathrm{pB}\left(\mathrm{I}_{2}, \lambda_{\max }\right.$ $=350 \mathrm{~nm}$ ), within $200 \mu \mathrm{s}$. pB returns to $\mathrm{pG}$ in hundreds of

$\dagger$ Permanent address: Department of Physics, University of Parma and CNR-INFM, Parco Area delle Scienze, 7/A, 43100 Parma, Italy.

$\ddagger$ Permanent address: Institute of Biological Information Processing 1, Research Centre Jülich, D-52425 Jülich, Germany. ms. ${ }^{11,12}$ Precursors of $\mathrm{pR}$ have been detected by means of femto- and picosecond spectroscopy. ${ }^{13-15}$ Given that PYP is small $(14 \mathrm{kDa})$, water soluble, stable, and relatively easy to crystallize, ${ }^{4,16}$ it has become a useful model system for the study of protein-chromophore interactions in photosensor proteins and for the changes they undergo during the lightinduced reactions. ${ }^{17}$

A key issue in photosensor proteins - all binding a prosthetic group for light absorption in the visible part of the solar radiation spectrum - is the understanding of how the structural changes induced in the chromophore by the primary photochemical event (i.e. isomerization in PYP) are transmitted to the protein and which kind of thermodynamic changes are produced. ${ }^{18}$ The early, thermally stable, intermediates appearing in the fs to short $\mu$ s time domain are of fundamental importance because the way the configuration of the active site is altered by light absorption, coupled with the amount of energy stored in these intermediates, determines the kinetics and yield of the subsequent steps. This concept has become clear during the study of the thermodynamics of the early events in mutated photosensors ${ }^{19,20}$ and of halorhodopsin in the presence of different anions. ${ }^{21}$

The strong coupling of the chromophore with the protein moiety restricts the chromophore mobility. E.g., isomerization takes place with only minor displacements in PYP, most 
probably through flipping of the thiol-esther linkage and not of the aromatic ring. ${ }^{2,23}$ The altered chromophore geometry nevertheless affects the protein microenvironment to such an extent that photosensors always exhibit structural changes accompanying the ns formation of a ground state red-shifted intermediate, i.e., $\mathrm{pR}$ in PYP, ${ }^{24} \mathrm{~K}$ or $\mathrm{K}$-like in archaeal rhodopsins, ${ }^{19-21,25,26}$ bathorhodopsin in bovine rhodopsin, ${ }^{27,28}$ $\mathrm{I}_{700}$ in phytochrome, ${ }^{29}$ and $\mathrm{LOV}_{660}$ in the LOV domains of phototropins. $^{18,30,31}$

The structural changes taking place upon formation of the red-shifted intermediates are readily detected as reaction volume changes $\left(\Delta V_{i}\right)$ by means of laser induced optoacoustic spectroscopy (LIOAS). This particular $\Delta V_{i}=\Delta V_{1}$, corresponds to the earliest detectable event by LIOAS. ${ }^{32}$ Although no net charge transfer occurs at this stage, the value of $\Delta V_{1}$ is in many cases similar to that measured for the formation of the charge separated state in photosynthetic units, attributed to electrostriction phenomena. ${ }^{33}$ This interpretation has been questioned $^{18}$ and in the case of the above mentioned photosensors, it appears that electrostriction cannot be the origin of $\Delta V_{1}$

Given that the largest protein conformational changes, concomitant with the formation of the signaling state, take place in later steps of the photoinduced transformations, occurring in $\mu$ s to $\mathrm{ms}$ and involving protein regions far from the chromophore, the observed values of $\Delta V_{1}$ most probably originate in rearrangements of weak interactions within the protein cavity containing the chromophore, e.g., changes in the number and strength of $\mathrm{HB}$ and electrostatic interactions of the chromophore with surrounding amino acids and/or with internal water molecules. Other effects such as an increase in void volume upon protein unfolding have also been considered. ${ }^{34}$

In this communication, we report LIOAS measurements with WT-PYP and its mutated variants E46Q-PYP and E46A-PYP, under identical conditions. The $\mathrm{pH}$ was in all cases 8.5 in order to have the main proportion in each of the three proteins with the deprotonated chromophore. Hydrogen bond formation between the chromophore phenolate and the $\mathrm{NH}_{2}$ group is still possible in the E46Q-PYP protein, but no proton transfer can occur between these groups. In fact, it has been shown that HB between Q46 and the phenolate oxygen in E46Q-PYP is of average length, having then less stability than the shorter HB from E46 in WT-PYP. The unusually short HB from Y42, on the other hand, remains unchanged in the E46QPYP parent state as in WT-PYP. ${ }^{7}$ In E46A-PYP, a HB is absent between A46 and the chromophore, although most probably the HB from Y42 is still present. These two mutant forms are then particularly interesting, given that the HB network centered around the phenolic oxygen is the core of the PYP photocycle and E46 has been shown to be a major determinant both of the absorption maximum (see Fig. 1) and of the apparent $\mathrm{p} K_{\mathrm{a}}$ value of the chromophore. This $\mathrm{p} K_{\mathrm{a}}$ increases from 2.8 in WT-PYP to 5.3 and 7.8 in E46Q-PYP and E46A-PYP, respectively. ${ }^{8,9}$ It is known that the E46Q mutation does not fundamentally affect the formation quantum yield of $\mathrm{pR}$ (vide infra), but has a strong effect on the kinetics of the photocycle. In fact, the isomerization is complete in far less than $1 \mathrm{~ns}$ in WT-PYP and in PYP-E46Q. ${ }^{35}$ The rate in PYP-E46Q at $\mathrm{pH} 8.5$ is about five times faster for the $\mathrm{pR}$ to $\mathrm{pB}$ transition and three times faster for the recovery of $\mathrm{pG}$ from $\mathrm{pB} .{ }^{36}$ The faster formation of $\mathrm{pR}$ in PYP-E46Q was attributed to the looser HB between the amide group and the chromophore in the parent state that facilitates the completion of chromophore isomerization and protein relaxation. ${ }^{37}$ FTIR experiments at room temperature confirmed this postulate, because they indicate that E46 remains protonated upon $\mathrm{pR}$ formation and that the HB with the phenolate oxygen on the chromophore is even strengthened in WT-PYP. ${ }^{23,38,39}$ This interpretation has been recently questioned by the results of

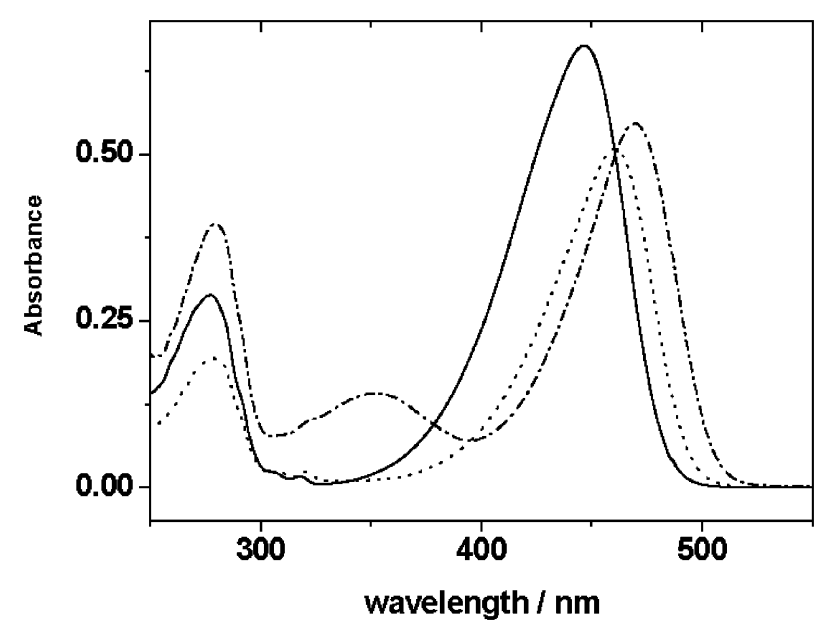

Fig. 1 Absorption spectra of (- - WT-PYP, (- - -) E46Q-PYP, and $(-\cdot-)$ E46A-PYP in $10 \mathrm{mM}$ Tris buffer, $\mathrm{pH}=8.5$, and $10{ }^{\circ} \mathrm{C}$.

time-resolved (150 ps) Laue crystallographic snapshots at room temperature and high crystallographic resolution $(1.6 \AA) .{ }^{40}$ The discrepancy will be analysed in the light of the present data.

Important for the data presented in this paper is the fact that $\mathrm{pR}\left(=\mathrm{I}_{1}\right)$ in all three cases (the WT and the two mutated proteins) is formed within the time considered "prompt" for the LIOAS experiments (see below). The formation of $\mathrm{pB}$, although faster in E46A and E46Q with respect to WTPYP, ${ }^{8,41}$ occurs with lifetimes that fall beyond the LIOAS time-window (a few $\mu$ s, see also the Results section).

We show in this paper that $\Delta V_{1}$ (identified as the structural volume change concomitant with $\mathrm{pR}$ formation, $\Delta V_{\mathrm{pR}}$ ) is not influenced by the E46Q mutation, whereas it is strongly changed by the E46A mutation. The data presented in this report also indicate that the arrangement of the HB network has a large influence on the transition of $\mathrm{pR}$ to a second redabsorbing intermediate $\mathrm{pR}^{\prime}$ with a lifetime of $1-2 \mu$ s at $4{ }^{\circ} \mathrm{C}$. The existence of an intermediate $\left(\mathrm{pR}^{\prime}\right)$ has been previously reported using time-resolved optical rotatory dispersion, ${ }^{42}$ and also transient absorbance spectroscopy (see ref. 42 for the discussion of this topic). However, a photothermal technique such as LIOAS is more sensitive to detect transitions involving the protein skeleton and its application permits the evaluation of the enthalpy and structural changes involved in the transition. ${ }^{43}$

Our results are in line with results from FTIR spectroscopy, ${ }^{23,35,38,39}$ confirming the key role of the HB network rearrangements in the formation of $\mathrm{pR}$ and point to a larger role of structural changes with respect to enthalpic changes in determining the subsequent kinetics. Furthermore, we also find that the relaxation in the hundreds of ns to short $\mu \mathrm{s},{ }^{43}$ is somewhat slower for E46Q-PYP and much slower for the E46A-PYP mutated protein than for the WT-PYP. This transition, attributed to a protein relaxation preceding the intramolecular proton transfer necessary for the formation of the signaling state $\mathrm{pB},{ }^{43}$ shows quite different activation parameters in the case of E46A-PYP, largely inhibited in its ability to participate in the $\mathrm{HB}$ network, whereas the activation parameters for the same transition in WT-PYP and in E46QPYP are similar.

\section{Experimental}

\section{Sample preparation}

PYP and site-directed mutants thereof (i.e., E46Q and E46A) were prepared and isolated as described by Kort et al. ${ }^{44}$ and Hendriks et al. ${ }^{10}$ as hexa-histidine tagged apo-proteins in Escherichia coli. The E46Q variant was made as described by 
Hendriks et al. ${ }^{10}$ The E46A mutation was introduced using the QuickChange kit (Stratagene) and with pHISP as a template. ${ }^{44}$ The sequences for the mutagenic primers for the E46A mutated protein were 5' GGCAACATCCTTCAGTACAACGCCG CGGCCGGCGACATCACCG $3^{\prime}$ and $5^{\prime}$ CGGTGATGTC GCCGGCCGCGGCGTTGTACTGAAGGATGTTGCC $3^{\prime}$ (the underlined bases indicate the mutated codons). The mutations were confirmed using nucleotide sequence analysis. Protein samples were used without removal of their hexa-histidinecontaining N-terminal tag in $10 \mathrm{mM}$ Tris $/ \mathrm{HCl}, \mathrm{pH}=8.5$.

The measurements were performed in Tris buffer $10 \mathrm{mM}$, $\mathrm{pH}=8.5\left(22^{\circ} \mathrm{C}\right)$. Due to the temperature dependence of the $\mathrm{pH}$ Tris-buffers the $\mathrm{pH}$ is not constant with temperature; it changes to about 9.1 at $4{ }^{\circ} \mathrm{C}$.

Absorption spectra were recorded with a UV-2102PC spectrophotometer (Shimadzu Germany, Duisburg, Germany).

Excitation for the LIOAS experiments was achieved by pumping a frequency-tripled pulse of a Nd:YAG laser (SL 456G, 6-ns pulse duration, Spectron Laser System, Rugby, Great Britain) into a Beta Barium Borate Optical Parametric Oscillator (OPO-C-355, bandwidth 420-515 nm, Laser Technik Vertriebs $\mathrm{GmbH}$, Ertestadt-Friesheim, Germany) as previously described. ${ }^{19}$ The beam was shaped by a $0.5 \times 6 \mathrm{~mm}$ slit. The set-up allowed a time resolution of $c a$. 20 ns by using deconvolution techniques. ${ }^{45}$ The laser wavelengths were 440 , 450 , and $460 \mathrm{~nm}$ for the experiments with WT-PYP, E46QPYP, and E46A-PYP, respectively. The experiments were performed in the linear regime of amplitude versus laser fluence. The total incident energy normally used was $c a .20$ $\mu \mathrm{J}$ pulse $e^{-1}$ (fluence $=666 \mu \mathrm{J} \mathrm{cm}^{-2}$ ). Solutions of New Coccine (FLUKA, Neu-Ulm, Germany) were used as calorimetric reference in the same buffer as PYP. ${ }^{46}$ Absorbance from sample and reference solutions were matched at \pm 0.001 absorbance units at each of the temperatures of the LIOAS measurements. This procedure was needed because the work was carried out at $\mathrm{pH}=8.5$, very near the $\mathrm{p} K_{\mathrm{a}}$ value of the PYP chromophore in E46A-PYP, ${ }^{47}$ where small temperature changes result in changes of the absorption spectrum due to the temperature dependence of the Tris-buffer. Since only the coloured deprotonated chromophore absorbs in the visible, the measurement always refers to the excitation of the species with the deprotonated chromophore. The variation in absorbance between 3.6 and $10{ }^{\circ} \mathrm{C}$ (the extremes for the LIOAS measurements) was $<10 \%$.

The time evolution of the pressure after laser excitation was assumed to be a sum of monoexponential functions. The deconvolution analysis yielded the fractional amplitudes $\left(\varphi_{i}\right)$ and the lifetimes $\left(\tau_{i}\right)$ of the transients (Sound Analysis 3000 , Quantum Northwest Inc., Spokane, WA). The time window was between $20 \mathrm{~ns}$ and $5 \mu \mathrm{s}$.

At every temperature, for each resolved $i$-th step, the fractional amplitudes $\varphi_{i}$ are a sum of the contribution from the fraction of energy released as heat $\left(\alpha_{i}\right)$ plus that from the structural volume change $\left(\Delta V_{i}\right)$, according to eqn. (1): $:^{32,48}$

$$
\varphi_{i}=\alpha_{i}+\frac{\Delta V_{i} \Phi_{i}}{E_{\lambda}}\left(\frac{c_{p} \rho}{\beta}\right)_{T}
$$

where $E_{\lambda}$ is the molar excitation energy, $\beta=(\partial V / \partial T)_{p} / V$ is the cubic thermal expansion coefficient, $c_{p}$ is the heat capacity at constant pressure, $\rho$ is the mass density of the solvent, and $\Phi_{i}$ the quantum yield of the $i$-step. The separation of $\alpha_{i}$ and $\Delta V_{i}$ was achieved by means of the two temperatures method (TT). ${ }^{49}$ The sample waveform was acquired at a temperature at which heat transport is zero, $T_{\beta=0}=3.6{ }^{\circ} \mathrm{C}$ for this buffer (i.e., the calorimetric reference gives no signal at this temperature), and at a slightly higher temperature $T_{\beta>0}\left(7\right.$ and $\left.10{ }^{\circ} \mathrm{C}\right)$. At $T_{\beta=0}$ the LIOAS signal is only due to structural volume changes, $\Delta V_{i}$. The reference for deconvolution was recorded at $T_{\beta>0}$, and eqns. (2a) and (2b) were then used to derive $\alpha_{i}$ and $\Delta V_{i}$

$$
\begin{aligned}
& \Phi_{i} \Delta V_{i}=\left.\varphi_{i}\right|_{T_{\beta=0}} E_{\lambda}\left(\frac{\beta}{c_{p} \rho}\right)_{T_{\beta>0}} \\
& \alpha_{i}=\left.\varphi_{i}\right|_{T_{\beta>0}}-\left.\varphi_{i}\right|_{T_{\beta=0}}
\end{aligned}
$$

Flash photolysis measurements were performed with the equipment previously described using excitation at $460 \mathrm{~nm} .{ }^{50}$ The pulses were of 5-6 $\mathrm{mJ}$ incident energy and the protein solutions had an absorbance $A(460)=c a$. 0.5 (the exact value depending on the sample). The bleaching of the respective parent form $\mathrm{pG}$ was followed at $460 \mathrm{~nm}$ for WT-PYP, E46QPYP, and E46A-PYP. The maximal bleaching in the pGabsorption band was taken as a measure of the $\mathrm{pB}$ formation quantum yield, $\Phi_{\mathrm{pB}}$ for each of the three proteins. $\Phi_{\mathrm{pB}}$ was considered equal to the quantum yield of formation of $\mathrm{pR}$, $\Phi_{\mathrm{pR}}$. Corrections were made for the small differences in the ground state absorption of the solutions. In view of the fact that the value of $\Phi_{\mathrm{pR}}$ for WT-PYP was previously accurately measured, ${ }^{24,51}$ the values of $\Phi_{\mathrm{pR}}$ for E46Q-PYP and for E46A$P Y P$ were determined at room temperature relative to those of WT-PYP. $\Phi_{\mathrm{pR}}$ for E46Q-PYP and E46A-PYP was calculated by using eqn. (3) and the molar absorption coefficients of the three PYP proteins at $460 \mathrm{~nm}\left[\varepsilon(460)=35490,{ }^{52} 53800,{ }^{8}\right.$ and $46028^{8} \mathrm{M}^{-1} \mathrm{~cm}^{-1}$ for WT-PYP, E46Q-PYP, and E46A-PYP, respectively].

$$
\begin{aligned}
\Phi_{\mathrm{pR}, \mathrm{mut}}= & \Phi_{\mathrm{pR}, \mathrm{wt}}[\varepsilon(\mathrm{wt}) / \varepsilon(\mathrm{mut})][\Delta A(460, \mathrm{mut}) / \\
& \Delta A(460, \mathrm{wt})]
\end{aligned}
$$

\section{Results}

The absorption spectra of the E46Q-PYP, E46A-PYP and WT-PYP are shown in Fig. 1. As previously reported, the E46Q mutation shifts the ground state absorption maximum from 446 to $462 \mathrm{~nm} .{ }^{36}$ The alanine mutation shifts the red band even more to the red.

The raw parameters measured by LIOAS afford the extensive enthalpy changes, $\Phi_{i} \Delta H_{i}$, and structural volume changes, $\Phi_{i} \Delta V_{i}$, per absorbed einstein. To determine the corresponding molar quantities, the $\Phi_{i}$ values were measured by flash photolysis with optical detection of the transient absorbance. The quantum yields obtained with eqn. (3) were $0.2 \pm 0.1$, and $0.2 \pm$ 0.1 for E46Q-PYP, and E46A-PYP, respectively, measured with WT-PYP (with $\Phi_{\mathrm{pR}}=0.33 \pm 0.05^{24,51}$ ) as the reference.

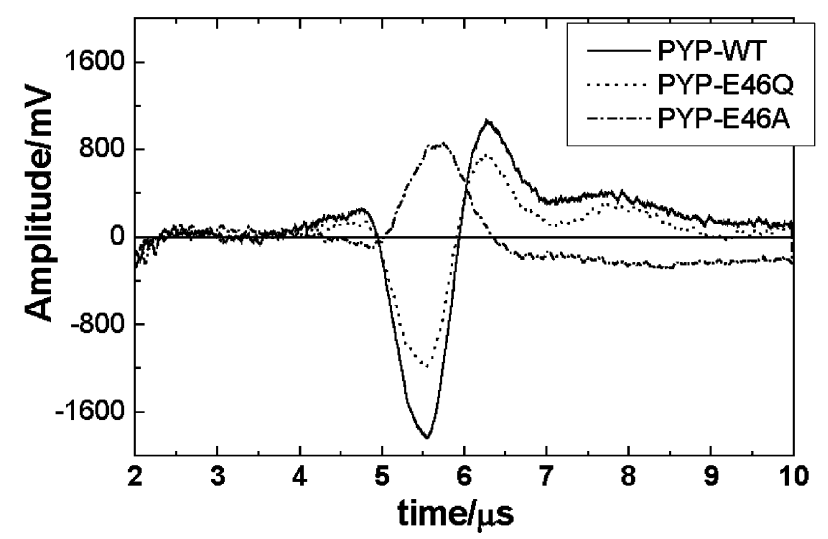

Fig. 2 LIOAS signals for (- - WT-PYP, (- - -) E46Q-PYP, and $(-\cdot-\cdot)$ E46A-PYP recorded at $T_{\beta=0}=3.6^{\circ} \mathrm{C}$. At this temperature the signals are only due to $\Delta V_{\mathrm{i}}$, i.e., the heat transport to the detector is zero. 
Table 1 Fractional heat $\left(\alpha_{i}\right)$ and structural volume change per absorbed einstein $\left(\Phi_{i} \Delta V_{i}\right)$ for each of the two steps detected by LIOAS upon excitation of mutated E46Q-PYP and E46A-PYP, and WT-PYP at wavelengths in the maximum of the respective absorption spectrum. The twotemperatures method was used $^{a}$

\begin{tabular}{lccc}
\hline & $\begin{array}{l}\text { WT-PYP } \lambda_{\text {exc }}=440 \mathrm{~nm} \\
\left(\equiv 271.8 \mathrm{~kJ} \mathrm{~mol}^{-1}\right)\end{array}$ & $\begin{array}{l}\text { E46Q-PYP } \lambda_{\text {exc }}=450 \mathrm{~nm} \\
\left(\equiv 265.7 \mathrm{~kJ} \mathrm{~mol}^{-1}\right)\end{array}$ & $\begin{array}{l}\text { E46A-PYP } \lambda_{\text {exc }}=460 \mathrm{~nm} \\
\left(\equiv 260 \mathrm{~kJ} \mathrm{~mol}^{-1}\right)\end{array}$ \\
\hline$\alpha_{1}(<10 \mathrm{~ns})$ & $0.82 \pm 0.05$ & $0.87 \pm 0.05$ & $0.87 \pm 0.08$ \\
$\Phi_{1} \Delta V_{\mathrm{pR}} / \mathrm{ml} \mathrm{mol}^{-1}$ & $-6.2 \pm 0.06$ & $-4 \pm 0.1$ & $1.4 \pm 0.3$ \\
$\alpha_{2}$ & $0.01 \pm 0.03$ & $0.05 \pm 0.03$ & $0.7 \pm 0.09$ \\
$\Phi_{2} \Delta V_{\mathrm{pR} \rightarrow \mathrm{pR}} / \mathrm{ml} \mathrm{mol}^{-1}$ & $0.22 \pm 0.14$ & $1070 \pm 300$ & $5.9 \pm 0.06$ \\
$\tau_{2} / \mathrm{ns}\left(3.6{ }^{\circ} \mathrm{C}\right)$ & $1040 \pm 500$ & $1520 \pm 270$ \\
${ }^{a}$ Signals with the reference solution were recorded at 7 and at $10{ }^{\circ} \mathrm{C}$ for E46Q-PYP, E46A-PYP, and for WT-PYP. \\
\hline
\end{tabular}

\section{LIOAS results: enthalpy and conformational changes}

The LIOAS signals for WT-PYP, E46Q-PYP, and E46A-PYP at $3.6{ }^{\circ} \mathrm{C}\left(T_{\beta=0}\right)$ are shown in Fig. 2 (each recorded at absorbance $A=0.17$, at the respective $\lambda_{\text {exc }}$; see Table 1 for the excitation wavelengths which in all cases were in the maximum of the red absorption band). The signals were best fitted by a sum of two exponential terms (see Fig. 3) containing information about the enthalpic and structural volume changes of the two transitions [see eqn. (1)]. After using the results obtained at $T_{\beta=0}$ and at $T_{\beta>0}$ with eqns. (2a) and (2b) the extensive values were calculated (Table 1).

The LIOAS experiments were also carried out using a different set of excitation wavelengths, i.e., exciting in the red flank of the respective pG absorption band (480, 490, $495 \mathrm{~nm}$ for WT-PYP, E46Q-PYP, and E46A-PYP, respectively). Also in this case the absorbance was $A=0.17$ at the respective excitation wavelength. The results are similar (Table 2), within experimental error [note that the $\alpha$ values depend on the excitation wavelength and should be lower for excitation with photons of lower energy, see eqns. (3a) and (3c) below] to those obtained for excitation in the blue flank of the respective absorption bands (Table 1).

The prompt process, with $\tau_{1}<20 \mathrm{~ns}$, corresponds to the formation of $\mathrm{pR} .{ }^{12}$ The time-resolved step, with $\tau_{2} c a .1 \mu \mathrm{s}$, has been already reported and should correspond to a protein relaxation leading to a transient state $\mathrm{pR}^{\prime} .{ }^{34,43}$ In fact, also time-resolved UV/Vis- and optical dichroism studies have found a $(5 \pm 1.5) \mu$ s step which may be associated, within the mutual experimental errors, with the same process. ${ }^{42}$ This step cannot be assigned to the much slower formation of $\mathrm{pB}^{\prime}$ or $\mathrm{pB}\left(=\mathrm{I}_{2}\right)$, albeit for E46A-PYP a fast component with lifetime $=$ $1.6 \mu$ s could be measured for this process at room temperature by time-resolved UV/Vis spectroscopy. ${ }^{42}$ We were not able to detect such a transition at $25^{\circ} \mathrm{C}$, probably due to the fact that the contribution from this fast component in the formation of a blue-shifted intermediate is much smaller than the dominant $20 \mu$ s one. ${ }^{41}$ The molar values of $\Delta H_{i}$ and $\Delta V_{i}$ for each step are obtained from the values in Tables 1 and 2 with eqns. (3a) through (3d), under the assumption that $\Phi_{\mathrm{pR}}=\Phi_{\mathrm{pR}^{\prime}}$ and neglecting radiative decays:

$$
\begin{gathered}
\Delta H_{\mathrm{pR}}=\frac{1-\alpha_{1}}{\Phi_{\mathrm{pR}}} E_{\lambda} \\
\Delta V_{\mathrm{pR}}=\frac{\Delta V_{1}}{\Phi_{\mathrm{pR}}} \\
\Delta H_{\mathrm{pR} \rightarrow \mathrm{pR}^{\prime}}=-\frac{\alpha_{2}}{\Phi_{\mathrm{pR}}} E_{\lambda} \\
\Delta V_{\mathrm{pR} \rightarrow \mathrm{pR}^{\prime}}=\frac{\Delta V_{2}}{\Phi_{\mathrm{pR}^{\prime}}}
\end{gathered}
$$

In these equations $\Delta H_{\mathrm{pR}}$ and $\Delta V_{\mathrm{pR}}$ are the molar enthalpic and structural volume change for the reaction from $\mathrm{pG}$ to $\mathrm{pR}$, and $\Delta H_{\mathrm{pR} \rightarrow \mathrm{pR}^{\prime}}$ and $\Delta V_{\mathrm{pR} \rightarrow \mathrm{pR}}$ are the molar enthalpy and structural volume change for the $\mathrm{pR}$ to $\mathrm{pR}^{\prime}$ reaction. The assumption $\Phi_{\mathrm{pR}}=\Phi_{\mathrm{pR}^{\prime}}$ is justified because no bleaching recovery is observed within the $\mathrm{pR}$ lifetime, that would indicate $\mathrm{pG}$ recovery from $\mathrm{pR}$.

The calculations afford the results reported in Table 3 (with the raw data from Table 1, i.e. excitation in the maximum of the respective absorption band) and in Table 4 (with the raw data in Table 2, i.e., excitation in the red flank of the respective absorption band).

The values of $\Delta V_{\mathrm{pR}}$ for WT-PYP and E46Q-PYP (Tables 3 and 4) are similar to those reported in the same temperature range (between 7 and $10{ }^{\circ} \mathrm{C}$ ) by Terazima, ${ }^{34}$ as well as to the value derived in our laboratory from temperature-dependent measurements. $^{24}$

The $\mathrm{pR}$ to $\mathrm{pR}^{\prime}$ transition is exothermic in all three cases when exciting in the respective absorption maximum, and also exothermic for WT-PYP and E46Q-PYP but endothermic for E46A-PYP for excitation in the red flank of the absorption band. However (see Discussion), the absolute value of $\alpha$ for this transition is so small that speculations about the enthalpic

\begin{tabular}{|c|c|c|c|}
\hline & $\begin{array}{l}\text { WT-PYP } \lambda_{\text {exc }}=480 \mathrm{~nm} \\
\left(\equiv 249.1 \mathrm{~kJ} \mathrm{~mol}^{-1}\right)\end{array}$ & $\begin{array}{l}\text { E46Q-PYP } \lambda_{\text {exc }}=485 \mathrm{~nm} \\
\left(\equiv 246.6 \mathrm{~kJ} \mathrm{~mol}^{-1}\right)\end{array}$ & $\begin{array}{l}\text { E46A-PYP } \lambda_{\mathrm{exc}}=495 \mathrm{~nm} \\
\left(\equiv 241.6 \mathrm{~kJ} \mathrm{~mol}^{-1}\right)\end{array}$ \\
\hline$\alpha_{1}(<10 \mathrm{~ns})$ & $0.78 \pm 0.04$ & $0.81 \pm 0.03$ & $0.80 \pm 0.01$ \\
\hline$\Phi_{1} \Delta V_{\mathrm{pR}} / \mathrm{ml} \mathrm{mol}^{-1}$ & $-5.3 \pm 0.02$ & $-3.2 \pm 0.2$ & $1.0 \pm 0.1$ \\
\hline$\alpha_{2}$ & $0.04 \pm 0.04$ & $0.03 \pm 0.06$ & $-0.03 \pm 0.14$ \\
\hline 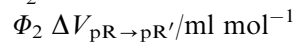 & $0.2 \pm 0.15$ & $0.95 \pm 0.09$ & $6.6 \pm 0.6$ \\
\hline$\tau_{2} / \mathrm{ns}\left(3.6^{\circ} \mathrm{C}\right)$ & $1070 \pm 300$ & $1110 \pm 120$ & $1740 \pm 100$ \\
\hline
\end{tabular}

Table 2 Fractional heat $\left(\alpha_{i}\right)$ and structural volume change per absorbed einstein $\left(\Phi_{i} \Delta V_{i}\right)$ for each of the two steps detected by LIOAS upon excitation of mutated E46Q-PYP and E46A-PYP, and wild type PYP at wavelengths in the red flank of the respective absorption spectrum. The two-temperatures method was used ${ }^{a}$ 
Table 3 Molar thermodynamic changes for WT-PYP, E46Q-PYP, and E46A-PYP calculated with eqns. (3a)-(3d) and the data listed in Table 1. Excitation in the maximum of the respective absorption spectrum. The red transient production quantum yields, $\Phi_{\mathrm{pR}}$, are included

\begin{tabular}{lccc}
\hline & WT-PYP & E46Q-PYP & E46A-PYP \\
\hline$\Phi_{\mathrm{pR}}{ }^{a}$ & $0.33 \pm 0.05$ & $0.2 \pm 0.1$ & $0.2 \pm 0.1$ \\
$\Delta H_{\mathrm{pR}} / \mathrm{kJ} \mathrm{mol}^{-1}$ & $140 \pm 70$ & $150 \pm 50$ & $154 \pm 100^{b}$ \\
$\Delta V_{\mathrm{pR}} / \mathrm{ml} \mathrm{mol}^{-1}$ & $-18 \pm 2$ & $-17 \pm 2$ & $+6 \pm 2$ \\
$\Delta H_{\mathrm{pR} \rightarrow \mathrm{pR}^{\prime} / \mathrm{kJ} \mathrm{mol}^{-1}}$ & $-8 \pm 45$ & $-57 \pm 40$ & $-35 \pm 15^{b}$ \\
$\Delta V_{\mathrm{pR} \rightarrow \mathrm{pR}^{\prime}} / \mathrm{ml} \mathrm{mol}^{-1}$ & $+0.6 \pm 0.5$ & $+3 \pm 1$ & $+26 \pm 10$
\end{tabular}

${ }^{a}$ Data obtained by flash photolysis with optical detection (see text). ${ }^{b}$ The errors for the $\Delta H$ values are very large and difficult to assess, but certainly $>50 \%$.

change should be avoided. Fluorescence is neglected since in all cases the fluorescence quantum yield is $<10^{-3}$.

The lifetime $\tau_{2}$ associated with the $\mathrm{pR} \rightarrow \mathrm{pR}^{\prime}$ transition is temperature dependent in the range between about 3 and $25^{\circ} \mathrm{C}$ (Fig. 4). The experimental values of $\tau_{2}$ collected in Table 5 were fitted with the Arrhenius eqn. (4),

$$
\frac{1}{\tau_{2}}=A \exp \left(-E_{\mathrm{a}} / R T\right)
$$

in which $E_{\mathrm{a}}$ is the activation energy, $T$ the absolute temperature, $R$ the gas constant, and $A$ the pre-exponential factor. The derived values for $E_{\mathrm{a}}$ and $A$ are listed in Table 5. Although the temperature range is very limited and the errors associated are large, especially for $A$, it is evident that the mutated E46A-PYP protein shows considerably larger temperature dependence than WT-PYP and E46Q-PYP.

\section{Discussion}

\section{The quantum yield of $p R\left(I_{1}\right)$ formation}

The concept that the $\mathrm{pG}$ bleaching measured $2 \mathrm{~ms}$ after the laser pulse is equal to the $\mathrm{pR}$ formation quantum yield $\Phi_{\mathrm{pR}}$ in the case of WT-PYP was supported by the LIOAS measurements of the photosaturation of the $\mathrm{pR} \rightleftarrows \mathrm{pG}$ equilibrium. ${ }^{51}$ For E46Q-PYP a value of $0.2 \pm 0.1$ was measured by the $\mathrm{pG}$ bleaching method, using the quantum yield value for WT-PYP as reference $\left(\Phi_{\mathrm{pR}}=\Phi_{\mathrm{pB}}=0.35 \pm 0.05\right)$. By applying a similar procedure the value $0.2 \pm 0.1$ was determined for the bleaching of $\mathrm{pG}$ in E46A-PYP. For this mutated protein it is not completely certain that the pG bleaching after $2 \mathrm{~ms}$ has the same value as $\Phi_{\mathrm{pR}}$. At $\mathrm{pH} 8.5$ there is an equilibrium between the deprotonated and the protonated chromophore in E46APYP and also the kinetics of the photocycle contains additional components in the short milliseconds time range. ${ }^{53}$ In fact, a $\mathrm{pH}$-dependent return to the ground state of the $\mathrm{pB}$ precursor

Table 4 Molar thermodynamic changes for WT-PYP, E46Q-PYP, and E46A-PYP calculated with eqns. (3a)-(3d) and the data listed in Table 2. Excitation in the red flank of the respective absorption spectrum. The red transient production quantum yields, $\Phi_{\mathrm{pR}}$, are included

\begin{tabular}{lccc}
\hline & WT-PYP & E46Q-PYP & E46A-PYP \\
\hline$\Phi_{\mathrm{pR}}{ }^{a}$ & $0.33 \pm 0.05$ & $0.2 \pm 0.1$ & $0.2 \pm 0.1$ \\
$\Delta H_{\mathrm{pR}} / \mathrm{kJ} \mathrm{mol}^{-1}$ & $157 \pm 70$ & $203 \pm 60$ & $220 \pm 100^{b}$ \\
$\Delta V_{\mathrm{pR}} / \mathrm{ml} \mathrm{mol}^{-1}$ & $-15 \pm 2$ & $-14 \pm 3$ & $+5 \pm 2$ \\
$\Delta H_{\mathrm{pR} \rightarrow \mathrm{pR}} / \mathrm{kJ} \mathrm{mol}^{-1}$ & $-28 \pm 50$ & $-18 \pm 36$ & $+33 \pm 15^{b}$ \\
$\Delta V_{\mathrm{pR} \rightarrow \mathrm{pR}} / \mathrm{ml} \mathrm{mol}^{-1}$ & $+0.6 \pm 0.5$ & $+4.2 \pm 2$ & $30 \pm 15$
\end{tabular}

${ }^{a}$ Data obtained by flash photolysis with optical detection (see text). ${ }^{b}$ The errors for the $\Delta H$ values are very large and difficult to assess, but certainly $>50 \%$.
Table 5 Activation parameters for the decay of $\mathrm{pR}$ into $\mathrm{pR}^{\prime}\left(\tau_{2}\right.$ in Tables 1 and 2). Temperature range: $3-25^{\circ} \mathrm{C}$

\begin{tabular}{llll}
\hline & WT-PYP & E46Q-PYP & E46A-PYP \\
\hline$A / \mathrm{s}^{-1}$ & $(1.5 \pm 2) \times 10^{11}$ & $(2.1 \pm 0.9) \times 10^{11}$ & $(8.4 \pm 0.03) \times 10^{13}$ \\
$E_{\mathrm{a} / \mathrm{kJ} \mathrm{mol}^{-1}} 28 \pm 6$ & $29 \pm 4$ & $42 \pm 8$ \\
\hline
\end{tabular}

(called $\mathrm{I}_{1}^{\prime}$ ) was observed. This was also the case for the E46QPYP photocycle. Notwithstanding this consideration, as a preliminary approach we use the value $\Phi_{\mathrm{pR}}=\Phi_{\mathrm{pB}}=0.2 \pm 0.1$ for E46A-PYP (see the Experimental section for the variation of absorption with temperature).

We note that the fractional heat evolved upon formation of $\mathrm{pR}\left(\alpha_{1}\right)$ is the same, within the experimental error, for excitation of all three protein samples with wavelengths corresponding to the maximum of the respective absorption spectrum (Table 1) as well as in the red flank (Table 2). In as much as $\alpha_{1}$ is a function of the product, $\Delta H_{\mathrm{pR}} \Phi_{\mathrm{pR}}$, i.e., the energy content of the $\mathrm{pR}$ intermediate, $\Delta H_{\mathrm{pR}}$, times the quantum yield for its formation, $\Phi_{\mathrm{pR}}$, [reorganization of eqn. (3a)] it is difficult to envisage an almost exact compensation of both terms. In fact, the $\Delta H_{\mathrm{pR}}$ values obtained when using the quantum yields determined independently by flash photolysis with optical detection, are the same for the three proteins within the large experimental error.
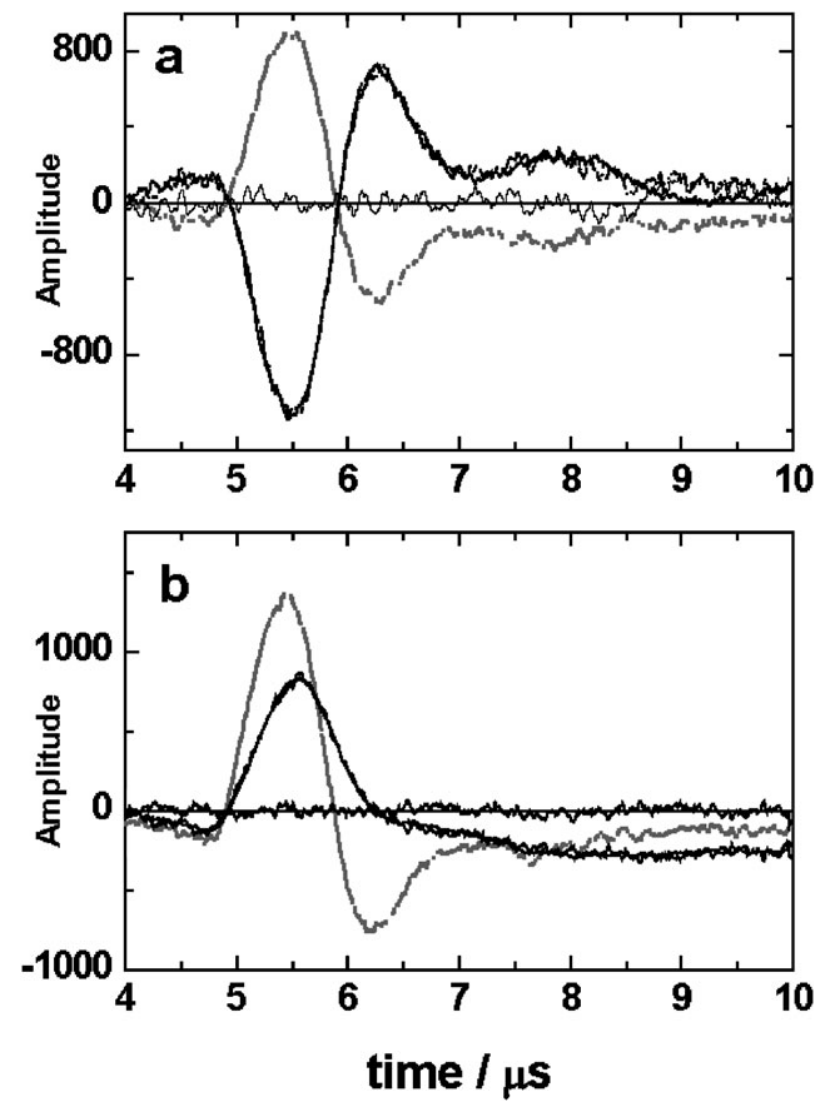

Fig. 3 LIOAS signals for (a) E46Q-PYP, (-) sample at $3.6{ }^{\circ} \mathrm{C}$, (grey) reference at $7^{\circ} \mathrm{C}$. The associated lifetimes are $\tau_{1}<1 \mathrm{~ns}$, and $\tau_{2}=$ $0.7 \mu$ s. (b) E46A-PYP, (-) sample at $3.6{ }^{\circ} \mathrm{C}$, (grey) reference at $7{ }^{\circ} \mathrm{C}$. The associated lifetimes are $\tau_{1}<1 \mathrm{~ns}$, and $\tau_{2}=1.8 \mu \mathrm{s}$. In each case the fitted curve from convolution of the reference signal with a sum of two exponentials, describing the time evolution of the pressure after excitation, overlaps the sample curve. The distribution of errors is depicted in each case in the centre of the figure. 


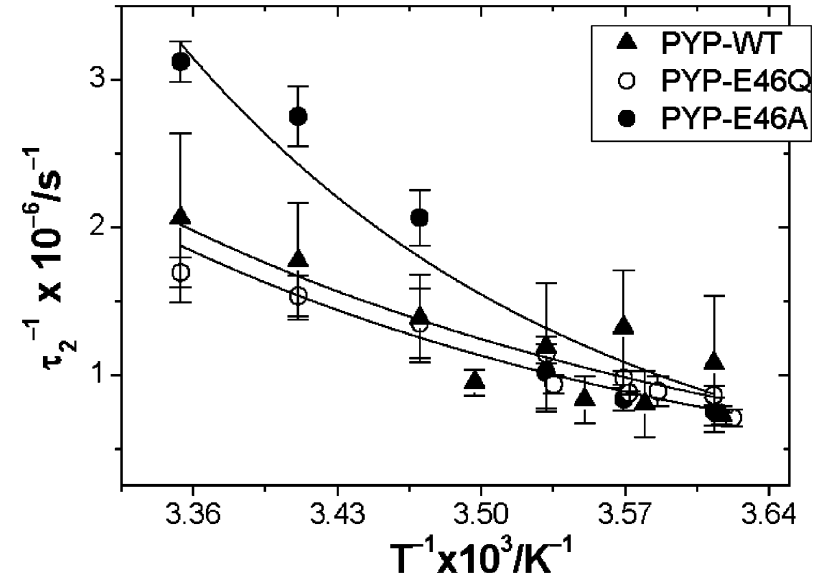

Fig. 4 Arrhenius plot (eqn. (4)) of the temperature dependence of $\tau_{2}$ in the range $3-25{ }^{\circ} \mathrm{C}$. The errors associated to each data point arise from averaging two sets of measurements and four waveforms for each set and temperature. For excitation wavelengths see Table 1.

\section{The thermodynamic parameters and the number of hydrogen bonds involved}

Both the $\Delta H_{\mathrm{pR}}$ and $\Delta V_{\mathrm{pR}}$ values are negligibly affected by the E46Q substitution. The formation of $\mathrm{pR}$, as monitored by FTIR, is accompanied by minor changes in the protein skeleton..$^{2,38,54}$ The phenolic oxygen carrying the negative change in the parent state $\mathrm{pG}$ is part of a $\mathrm{HB}$ network involving directly three adjacent residues (E46, T50, and Y42) with no intervening water molecules. ${ }^{5,7}$ The crystal structure of a cryotrapped early intermediate, ${ }^{55}$ precursor of $\mathrm{pR}$, shows very little changes in the $\mathrm{HB}$, whereas it has been reported that E46 strengthens the $\mathrm{HB}$ with the chromophore in $\mathrm{pR} . .^{22,38,54}$ In a recent high resolution analysis of the cryo-trapped species accumulated upon excitation of WT-PYP as well as of E46Q-PYP, three species - all precursors of $\mathrm{pR}$ - were found which are identical for the two proteins. In all three species the HB between E46 or Q46 and the phenolate oxygen remains constant upon isomerization. ${ }^{56}$ This indicates a heterogeneity of the intermediates (confirmed also by recent resonance Raman measurements) ${ }^{57}$ but also indicates that the very early stages of the photocycle are indistinguishable for both proteins. ${ }^{56}$

The most plausible interpretation of the negative and similar $\Delta V_{\mathrm{pR}}$ values in WT-PYP and in E46Q-PYP is that there is a strengthening of the HB network around the chomophore. This interpretation agrees with the room-temperature FTIR studies $^{23,35}$ which showed that the HB between the chromophore and Q46 is retained in the period immediately subsequent to isomerization. In other words, the isomerization of the chromophore causes an overall shortening of the total chromophore length. This shortening in turn drags together the amino acids hydrogen bonded to it.

Recent room-temperature, time-resolved Laue experiments with E46Q-PYP show that the HB between the chromophore and Q46 is broken at a later stage, though faster than in WT-PYP and the HB between the chromophore and Y42 is preserved, although lengthened, relative to the dark state. ${ }^{40,58}$

Rajagopal et al. ${ }^{40}$ report the presence of two intermediates (in the crystal) with lifetimes of 260 and $770 \mathrm{~ns}$. Should the 260 ns state (called IE1) correspond to the $\mathrm{pR}$ state observed in our LIOAS experiment, we could not attribute the $\Delta V_{\mathrm{pR}}$ contraction to a strengthening of the HB with E46 (or Q46), since in IE1 the HB is disrupted. However, most likely, in solution we are observing an earlier state.

With E46A-PYP the effect is different. Although the energy level of $\mathrm{pR}$ for this mutated protein is similar to that for WTPYP and for E46Q-PYP, $\Delta V_{\mathrm{pR}}$ is even positive, probably indicating just an enlargement of the already looser protein cavity upon isomerization of the chromophore. The E46A mutation influences $\mathrm{pR}$ formation (and decay, vide infra) through its remarkable influence on the HB network in the vicinity of the chromophore phenolic ring. ${ }^{22}$ In fact, in all our previous studies with photosensors with an isomerizable chromophore, an expansion was observed concomitant with the sub-ns formation of the red-shifted intermediate upon isomerization. 18

It is interesting to speculate that in view of the fact that the isomerization of the chromophore in E46A-PYP affords an expansion of $15 \mathrm{ml} \mathrm{mol}^{-1}$, the difference with the contraction in WT-PYP and in E46Q-PYP $\left(-5 \mathrm{ml} \mathrm{mol}^{-1}\right.$, see Table 4), i.e., ca. $-20 \mathrm{ml} \mathrm{mol}^{-1}$, should represent the contraction of the HB network around the chromophore in WT-PYP and E46QPYP. This speculation does not take into account the possible subsidiary interactions created in the mutated E46A-PYP. However, this thought is interesting because it means that the large positive volume change (probably associated with a large positive entropic term), produced by the isomerization, compensates the large HB contraction, probably associated with a large negative entropic term. Thus, the formation of $\mathrm{pR}$ seems to be mainly determined by the enthalpic term, since its enthalpy level is already about $50 \%$ below the $0-0$ band of PYP.

Model studies have shown that shortening of one HB from water to a $\mathrm{CN}$ substituent in $\mathrm{Ru}^{\mathrm{II}}$ bipyridine cyano complexes results in a contraction of $c a .4 \mathrm{ml} \mathrm{mol}^{-1}{ }^{59,60}$ Should this be a general value for such a shortening, the value determined for WT-PYP and E46Q-PYP would represent the contraction of 4-5 HB around the chromophore in $\mathrm{pR}$.

As observed for halorhodopsin ${ }^{21}$ and sensory rhodopsins, ${ }^{61}$ also in WT-PYP and its mutated derivatives, the conformational and structural changes occurring during the early steps, albeit involving minor modifications in the overall protein structure, drive the rest of the photocycle.

\section{The microsecond intermediate}

The lifetime $\tau_{2}$ associated with the time-resolved step in LIOAS is similar, albeit the associated errors are large. This step is definitely slower for E46A-PYP and is characterized by minimal differences in the heat evolved between the three proteins [taking into account the large error in the very small value of the extensive property $\alpha_{2}$, from which the enthalpy change is derived, eqn. (3c)]. There is, however, a large difference in the values of $\Delta V_{\mathrm{pR} \rightarrow \mathrm{pR}}$, i.e., a small expansion for WT-PYP, a larger one for E46Q-PYP, and a much larger one for E46APYP. We support the concept already outlined by Terazima and coworkers, ${ }^{43}$ that this process is due to rearrangements of the weak interactions in the active site.

The larger value of $\Delta V_{\mathrm{pR} \rightarrow \mathrm{pR}^{\prime}}$ for E46Q-PYP, is indicative of a larger conformational freedom of the weaker HB between the chromophore and the adjacent amino acid at position 46 . This interpretation would be in line with the one given above regarding the comparison of our data and the FTIR data at room temperature. ${ }^{23}$

Our present results indeed indicate that the HB perturbation influences the $\mathrm{pR}$ to $\mathrm{pR}^{\prime}$ transition, in view of the larger value of $\Delta V_{\mathrm{pR} \rightarrow \mathrm{pR}}$ in E46Q-PYP than in the WT, whereas it does not influence the value of $\Delta V_{\mathrm{pR}}$, concomitant with $\mathrm{pR}$ formation.

The larger expansion during the $\mathrm{pR}$ to $\mathrm{pR}^{\prime}$ step for the case of E46A-PYP (which cannot form the corresponding HB) should again indicate a very large entropic change, i.e., a larger number of hydrogen bonds are rearranged. This is also reflected in the large $A$ factor determined from the temperature dependence of the rate of the $\mathrm{pR}$ to $\mathrm{pR}^{\prime}$ transition (Table 5). However, the step is slower in E46A-PYP, due to a higher activation energy. Therefore, this step shows a partial entropyenthalpy compensation effect, typical of HB-controlled transitions. ${ }^{62}$ This effect documents the importance of the HB network in assisting the formation of the activated state for this transition. In other words, the chromophore cavity is so 
disrupted in its HB structure in E46A-PYP as to strongly perturb the activated transition to the $\mathrm{pR}^{\prime}$ transient, i.e., on the way to formation of the $\mathrm{pB}$ signalling state. Probably the signalling state is produced in the mutated protein through an alternative way to that in WT-PYP.

We note that UV-Vis 'silent' intermediates were observed in our laboratory with other chromoproteins using LIOAS. With a mutated sensory rhodopsin II from Natronobacterium salinarum (pSRII-D75N) a UV-Vis silent species with a $400 \mathrm{~ns}$ lifetime independent of temperature in the $6.5-52{ }^{\circ} \mathrm{C}$ range was observed. ${ }^{19}$ This species decays to the optically visible species $\mathrm{K}_{565}$. A similar transition has been observed by step-scan FTIR with bacteriorhodopsin. ${ }^{63}$ In the case of bacteriorhodopsin, reconstituted with isomerization-inhibited 5.12-translocked retinal, a UV-Vis optically silent $300 \mathrm{~ns}$ intermediate was observed and attributed to protein relaxation after radiationless deactivation of the $12 \mathrm{ps}$ intermediate produced upon excitation of the non-isomerizable chromophore. ${ }^{64}$

\section{Conclusions}

Comparison of the results from time-resolved LIOAS with WT-PYP and the two mutated proteins, E46Q-PYP and E46AWT in which the possibility to form an HB between the chromophore phenolate and the residue at position 46 is either modified or prevented, respectively, has allowed to establish that the lack of that $\mathrm{HB}$ strongly influences the structural changes concomitant already with the production of the first intermediate, $p R$. Interestingly, the quantum yield for the production of $\mathrm{pR}$ is not strongly affected by the mutations. The $\mathrm{pR}$ energy content is also not affected (within the relatively large error bars) by the mutations. In contrast, the structural volume changes are strongly affected going from a relatively large contraction of $c a .15 \mathrm{ml} \mathrm{mol}{ }^{-1}$ for $\mathrm{pR}$ formation in WT-PYP and E46Q-PYP to an expansion of $c a .5 \mathrm{ml} \mathrm{mol}^{-1}$ in E46Q-PYP. We attribute the contractions concomitant with $\mathrm{pR}$ formation preferentially to contraction of the HB network around the chromophore (between 4 and 5 hydrogen bonds) as a consequence of its isomerization which causes a decrease in its overall length. This drags together the aminoacids linked to it. The LIOAS technique afforded a clear identification of the next intermediate, $\mathrm{pR}^{\prime}$, difficult to detect by optical methods. The activation parameters for $\mathrm{pR}$ decay into $\mathrm{pR}^{\prime}$ are drastically enlarged for E46Q-PYP, which reinforces the important role played by Glu46 in providing the proper cavity arrangement for the correct functioning of the phototransformation. Thus, application of LIOAS to PYP in solution yields information crucial to the understanding of the mechanism of internal proton movements preceding the formation of the signalling state. The large contraction in WT-PYP is a structural characterization of this process. The absence of this process in E46A-PYP, which in spite of the inhibition produces a $\mathrm{pR}$ state and eventually the signalling state (albeit with lower yield and slower than WT-PYP), shows that the protein can find alternative paths to reach the signalling state. None of the theoretical models on PYP have, so far, properly taken into account these $\mathrm{HB}$ rearrangements nor properly predicted the associated rate of the intramolecular proton transfer. Yet, for a better understanding of the PYP mechanism, it is crucial to gain knowledge by other methods about the movement of water molecules during the photocycle.

\section{Abbreviations}

\section{E46A-PYP}

E46Q-PYP
Mutated photoactive yellow protein with glutamate 46 exchanged by alanine Mutated photoactive yellow protein with glutamate 46 exchanged by glutamine (continued)

\begin{tabular}{ll}
\hline HB & Hydrogen bond(s) \\
LIOAS & Laser-induced optoacoustic spectroscopy \\
pB & Blue-shifted intermediate \\
pG & Parent state \\
pR $\left(=\mathrm{I}_{1}\right)$ & Early red-shifted intermediate \\
pR' & Second-pR-like-intermediate of PYP \\
WT-PYP & Wild type photoactive yellow protein \\
$\Delta V_{1}$ & Structural volume change concomitant \\
& with pR formation
\end{tabular}

\section{Acknowledgements}

The able technical assistance of Heike Deinert and Simone Möllenbeck is gratefully acknowledged. K. J. H and M. v.d.H. would like to thank Dr Sergey Yeremenko for his help with the quantum yield determinations.

\section{References}

1 W. W. Sprenger, W. D. Hoff, J. P. Armitage and K. J. Hellingwerf, J. Bacteriol., 1993, 175, 3096-3104.

2 B. L. Taylor and I. B. Zhulin, Microbiol. Mol. Biol. Rev., 1999, 63, 479-506.

3 W. D. Hoff, P. Düx, K. Hard, B. Devreese, I. M. NugterenRoodzant, W. Crielaard, R. Boelens, R. Kaptein, J. van Beeumen and K. J. Hellingwerf, Biochemistry, 1994, 33, 13959-13962.

4 M. Baca, G. E. O. Borgstahl, M. Boissinot, P. M. Burke, D. R. Williams, K. A. Slater and E. D. Getzoff, Biochemistry, 1994, 33, $14369-14377$.

5 G. E. O. Borgstahl, D. R. Williams and E. D. Getzoff, Biochemistry, 1995, 34, 6278-6287.

6 M. Kim, R. A. Mathies, W. D. Hoff and K. J. Hellingwerf, Biochemistry, 1995, 34, 12669-12672.

7 S. Anderson, S. Crosson and K. Moffat, Acta Crystallogr., Sect. D, 2004, 60, 1008-1016.

8 Y. Imamoto, H. Koshimizu, K. Mihara, O. Hisatomi, T. Mizukami, K. Tsujimoto, M. Kataoka and F. Tokunaga, Biochemistry, 2001, 40, 4679-4685.

9 W. D. Hoff, I. H. M. Van Stokkum, J. Gural and K. J. Hellingwerf, Biochim. Biophys. Acta, 1997, 1322, 151-162.

10 J. Hendriks, T. Gensch, L. Hviid, M. A. van der Horst, K. J. Hellingwerf and J. J. van Thor, Biophys. J., 2002, 82, 1632-1643.

11 T. E. Meyer, E. Yakali, M. A. Cusanovich and G. Tollin, Biochemistry, 1987, 26, 418-423.

12 W. D. Hoff, I. H. M. van Stokkum, H. J. van Ramesdonk, M. E. van Brederode, A. M. Brouwer, J. C. Fitch, T. E. Meyer, R. van Grondelle and K. J. Hellingwerf, Biophys. J., 1994, 67, 1691-1705.

13 L. Ujj, S. Devanathan, T. E. Meyer, M. A. Cusanovich, G. Tollin and G. H. Atkinson, Biophys. J., 1998, 75, 406-412.

14 S. Devanathan, A. Pacheco, L. Ujj, M. Cusanovich, G. Tollin, S. Lin and N. Woodbury, Biophys. J., 1999, 77, 1017-1023.

15 M. Vengris, M. A. van der Horst, G. Zgrablić, I. H. M. van Stokkum, S. Haacke, M. Chergui, K. J. Hellingwerf, R. van Grondelle and D. S. Larsen, Biophys. J., 2004, 87, 1848-1857.

16 D. M. F. van Aalten, W. Crielaard, K. J. Hellingwerf and L. Joshua-Tor, Protein Sci., 2000, 9, 64-72.

17 K. J. Hellingwerf, J. Hendriks and T. Gensch, J. Phys. Chem. A, 2003, 107, 1082-1094.

18 A. Losi and S. E. Braslavsky, Phys. Chem. Chem. Phys., 2003, 5, 2739-2750

19 A. Losi, A. A. Wegener, M. Engelhard, W. Gärtner and S. E. Braslavsky, Biophys. J., 2000, 78, 2581-2589.

20 A. Losi, S. E. Braslavsky, W. Gärtner and J. L. Spudich, Biophys J., 1999, 76, 2183-2191.

21 A. Losi, A. A. Wegener, M. Engelhard and S. E. Braslavsky, Photochem. Photobiol., 2001, 74, 495-503.

22 A. H. Xie, W. D. Hoff, A. R. Kroon and K. J. Hellingwerf, Biochemistry, 1996, 35, 14671-14678.

23 R. Brudler, R. Rammelsberg, T. T. Woo, E. D. Getzoff and K. Gerwert, Nature Struct. Biol., 2001, 8, 265-270.

24 M. E. van Brederode, T. Gensch, W. D. Hoff, K. J. Hellingwerf and S. E. Braslavsky, Biophys. J., 1995, 68, 1101-1109. 
25 D. Zhang and D. Mauzerall, Biophys. J., 1996, 71, 381-388.

26 A. Losi, A. A. Wegener, M. Engelhard, W. Gärtner and S. E. Braslavsky, Biophys. J., 1999, 77, 3277-3286.

27 J. M. Strassburger, W. Gärtner and S. E. Braslavsky, Biophys. J., 1997, 72, 2294-2303.

28 T. Gensch, J. Strassburger, W. Gärtner and S. E. Braslavsky, Isr. J. Chem., 1998, 38, 231-236.

29 T. Gensch, M. S. Churio, S. E. Braslavsky and K. Schaffner, Photochem. Photobiol., 1996, 63, 719-725.

30 A. Losi, E. Polverini, B. Quest and W. Gärtner, Biophys. J., 2002 82, 2627-2634

31 A. Losi, T. Kottke and P. Hegemann, Biophys. J., 2004, 86, 1051-1060.

32 S. E. Braslavsky and G. E. Heibel, Chem. Rev., 1992, 92, 1381-1410

33 D. Mauzerall, J. M. Hou and V. A. Boichenko, Photosynth. Res., 2002, 74, 173-180.

34 M. Terazima, Bull. Chem. Soc. Jpn., 2004, 77, 23-41.

35 M. L. Groot, L. J. G. W. van Wilderen, D. S. Larsen, M. A. van der Horst, I. H. M. van Stokkum, K. J. Hellingwerf and R. van Grondelle, Biochemistry, 2003, 42, 10054-10059.

36 U. K. Genick, S. Devanathan, T. E. Meyer, I. L. Canestrelli, E. Williams, M. A. Cusanovich, G. Tollin and E. D. Getzoff, Biochemistry, 1997, 36, 8-14.

37 S. Devanathan, S. Lin, M. A. Cusanovich, N. Woodbury and G Tollin, Biophys. J., 2000, 79, 2132-2137.

38 W. D. Hoff, W. D. A. Xie, I. H. M. van Stokkum, X. J. Tang, J. Gural, A. R. Kroon and K. J. Hellingwerf, Biochemistry, 1999, 38, 1009-1017.

39 A. H. Xie, L. Kelemen, J. Hendriks, B. J. White, K. J. Hellingwerf and W. D. Hoff, Biochemistry, 2001, 40, 1510-1517.

40 S. Rajagopal, S. Anderson, V. Srajer, M. Schmidt, R. Pahl and K. Moffat, Structure, 2005, 13, 55-63.

41 B. Borucki, S. Devanathan, H. Otto, M. A. Cusanovich, G. Tollin and M. P. Heyn, Biochemistry, 2002, 41, 10026-10037.

42 E. Chen, T. Gensch, A. B. Gross, J. Hendriks, K. J. Hellingwerf and D. S. Kliger, Biochemistry, 2003, 42, 2062-2071.

43 K. Takeshita, Y. Imamoto, M. Kataoka, K. Mihara, F. Tokunaga and M. Terazima, Biophys. J., 2002, 83, 1567-1577.

44 R. Kort, W. D. Hoff, M. van West, A. R. Kroon, S. M. Hoffer, K. H. Vlieg, W. Crielaand, J. J. van Beeumen and K. J. Hellingwerf, EMBO J., 1996, 15, 3209-3218.
45 J. E. Rudzki, J. L. Goodman and K. S. Peters, J. Am. Chem. Soc., 1985, 107, 7849-7854.

46 S. Abbruzzetti, C. Viappiani, D. H. Murgida, R. Erra-Balsells and G. M. Bilmes, Chem. Phys. Lett., 1999, 304, 167-172.

47 S. Devanathan, R. Brudler, B. Hessling, T. T. Woo, K. Gerwert, E. D. Getzoff, M. A. Cusanovich and G. Tollin, Biochemistry, 1999, 38, 13766-13772

48 J. Rudzki-Small, L. J. Libertini and E. W. Small, Biophys. Chem., 1992, 42, 29-48.

49 S. Malkin, M. S. Churio, S. Shochat and S. E. Braslavsky, J. Photochem. Photobiol., B, 1994, 23, 79-85.

50 J. Hendriks, I. H. M. van Stokkum, W. Crielaard and K. J. Hellingwerf, FEBS Lett., 1999, 458, 252-256.

51 T. Gensch, K. J. Hellingwerf, S. E. Braslavsky and K. Schaffner, J. Phys. Chem. A, 1998, 102, 5398-5405.

52 T. E. Meyer, G. Tollin, J. H. Hazzard and M. A. Cusanovich, Biophys. J., 1989, 56, 559-564.

53 B. Borucki, H. Otto, C. P. Joshi, C. Gasperi, M. A. Cusanovich, S. Devanathan, G. Tollin and M. P. Heyn, Biochemistry, 2003, 42, 8780-8790.

54 Y. Imamoto, Y. Shirahige, F. Tokunaga, T. Kinoshita, K. Yoshihara and M. Kataoka, Biochemistry, 2001, 40, 8997-9004.

55 R. Kort, K. J. Hellingwerf and R. B. G. Ravelli, J. Biol. Chem., 2004, 279, 26417-26424.

56 S. Anderson, V. Šrajer and K. Moffat, Photochem. Photobiol., 2004, 80, 7-14.

57 M. Unno, M. Kumauchi, N. Hamada, F. Tokunaga and S. Yamauchi, J. Biol. Chem., 2004, 279, 23855-23858.

58 S. Anderson, V. Srajer, R. Pahl, S. Rajagopal, F. Schotte, P. Anfinrud, M. Wulff and K. Moffat, Structure, 2004, 12 1039-1045.

59 J.-L. Habib Jiwan, B. Wegewijs, M. T. Indelli, F. Scandola and S E. Braslavsky, Recl. Trav. Chim. Pays-Bas, 1995, 114, 542-548.

60 C. D. Borsarelli and S. E. Braslavsky, J. Phys. Chem. B, 1998, 102, 6231-6238

61 A. Losi, A. A. Wegener, M. Engelhard and S. E. Braslavsky, J. Am. Chem. Soc., 2001, 123, 1766-1767.

62 E. Grunwald and C. Steel, J. Am. Chem. Soc., 1995, 117, 5687-5692

63 A. K. Dioumaev and M. S. Braiman, J. Phys. Chem. B, 1997, 101 1655-1662.

64 A. Losi, I. Michler, W. Gärtner and S. E. Braslavsky, Photochem Photobiol., 2000, 72, 590-597. 